\title{
Article
}

\section{Kenyan Women Bearing the Cost of Climate Change}

\author{
Elizabeth M. Allen *, Leso Munala *(D) and Julie R. Henderson
}

Public Health Department, St. Catherine University, St. Paul, MN 55105, USA; jrhenderson660@stkate.edu

* Correspondence: emallen641@stkate.edu (E.M.A.); lmunala@stkate.edu (L.M.); Tel.: +651-690-6021 (E.M.A.); +651-690-6265 (L.M.)

check for updates

Citation: Allen, E.M.; Munala, L.; Henderson, J.R. Kenyan Women Bearing the Cost of Climate Change. Int. J. Environ. Res. Public Health 2021, 18, 12697. https://doi.org/ 10.3390/ijerph182312697

Academic Editors: Lee Smith and Igor Grabovac

Received: 28 October 2021

Accepted: 22 November 2021

Published: 2 December 2021

Publisher's Note: MDPI stays neutral with regard to jurisdictional claims in published maps and institutional affiliations.

Copyright: (c) 2021 by the authors. Licensee MDPI, Basel, Switzerland. This article is an open access article distributed under the terms and conditions of the Creative Commons Attribution (CC BY) license (https:// creativecommons.org/licenses/by/ $4.0 /)$.

\begin{abstract}
Climate change-induced crises can aggravate intimate partner violence (IPV); the loss of income when weather affects the agricultural industry can exacerbate violence at home. In Kenya, climate change has increased precipitation during the rainy season and raised temperatures during the dry season, resulting in floods and droughts. For $75 \%$ of Kenyans, agricultural activities are their primary source of income. This research aims to assess patterns in IPV and severe weather events (SWE). We examined Integrated Public Use Microdata Series-Demographic Health Survey (IPUMSDHS) data from 2008 and 2014 for IPV severity and frequency. We used Emergency Events Database (EM-DAT) data along with GPS coordinates to identify SWEs (defined as any flood >10 days) by county in Kenya. Overall, women were more likely to experience IPV if their spouse worked in agriculture (Odds Ratio $(\mathrm{OR})=1.22,95 \%$ Confidence Interval $(\mathrm{CI}): 1.10-1.36$ ). There was a $60 \%$ increase in the odds of reporting IPV in counties that experienced an SWE as compared to counties that did not experience an SWE (OR $=1.60,95 \%$ CI: 1.35-1.89). This analysis further supports the growing body of research that suggests a relationship between climate change-related weather events and violence against women.
\end{abstract}

Keywords: intimate partner violence; climate change; women; Kenya; severe weather; floods; environmental health; IPUMS-DHS

\section{Introduction}

In the wake of environmental tragedies, efforts focus on immediate healthcare needs and rebuilding infrastructures and economies. The differential effects among men and women, namely, the social and human costs, are often overlooked. Extreme weather patterns can put women in more vulnerable positions and often lead to increases in violence against women. As the number of severe environmental tragedies increases, so will the prevalence of intimate partner violence (IPV).

The pattern of environmentally associated violence has been documented both during and after extreme weather events. For example, rates of gender-based violence increased from 4.6/100,000 per day to 16.3/100,000 per day after Hurricane Katrina in 2005 [1]. Similarly, in the aftermath of Cyclones Vania and Atu that hit Vanuatu, there was a 300\% increase in new domestic violence victims seeking care at the Tanna Women's Counseling Centre [2]. Increasing temperatures significantly reduce well-being [3] and increase overall violence [4]. This is also shown specifically with IPV [5]. In a longitudinal analysis conducted in Spain, the risk of IPV increased by $40 \%$ three days after the heatwave. Police reports of violence and helpline calls also modestly increased post heatwave [5].

In many parts of the world, climate change directly affects the lives of women and girls daily, more so than for men and boys. Weather-related chores have been shown to increase women's risk of sexual assault and domestic violence, decrease their time spent in school, and thus decrease women's ability to achieve economic independence [6]. For example, in many parts of the world, women bear the responsibility of fetching water for the household. With the increased intensity of droughts, women need to travel further to reach water sources, and the longer travel time increases women and girls' risk of sexual 
assault [7]. This increase in travel time can also decrease the time girls have for school, further disempowering women.

Weather-related disasters because of climate change can place a number of stresses on a family. Crop destruction, loss of livestock, and loss of property resulting in both financial loss and food shortage place a significant burden on those who need to provide for their families [8]. Changing weather patterns have challenged and will continue to challenge farmers' decisions about when to plant their crops [9]. Moreover, farmers are finding it harder to consistently grow enough food to meet increasing demands [10]. Future predictions for the next century include a wetter rainy season leading to more common and more severe flooding, more severe droughts due to increasing temperatures, and a decrease in both crop yields and livestock production [11].

In this paper, we focus on the relationship between severe weather events in Kenya and the social costs to women. The agricultural industry accounts for an estimated 75 percent of informal employment and is the principal source of rural income and livelihoods [12,13]. The World Bank estimates that most farmers in Kenya, $70-80 \%$ of the farming community, rely on small-scale subsistence farms [13]. In 2020, agriculture accounted for 33\% of Kenya's gross domestic product; $20 \%$ of Kenya's landmass is adequate for farming [12]. Irrigation of this cropland is extremely rare, with $98 \%$ of this land dependent on rainfall alone [12]. However, since the 1970s, the average rainfall during the long season has decreased by $100 \mathrm{~mm}$.

During periods of economic stress, alcohol consumption often increases, which is directly associated with increases in domestic violence [14,15]. When families are negatively affected by severe weather, men may express anxiety and frustration by directing emotional, physical, and/or sexual violence against their partners [6,8]. Moreover, as small-scale subsistence farmers rely solely on the production of their farms to provide for their families, a natural disaster has detrimental effects on their livelihoods, which can be particularly devastating in Kenya due to such a vast small-scale subsistence farming economy [13]. As we see increases in severe weather events, we will also see increases in intimate partner violence around the globe.

Severe weather events (SWE) are interrupting the agriculture industry as weather patterns become more unpredictable. The impact of increased SWEs on the agricultural industry leads to increased stress for families along with decreased food affordability, which could result in millions of people reaching an extreme level of poverty $[8,16,17]$. For populations that routinely struggle with food insecurity, the negative impact is multiplied. The 2014 Kenya Demographic and Health Survey showed high levels of chronic food insufficiency for Kenyans, with $23 \%$ of urban household respondents and $36 \%$ of rural household respondents acknowledging not having enough food to eat during the seven days prior to the survey [18].

The frequency and intensity of some extreme weather events have increased and will continue to increase as a consequence of global climate change [19]. Some of these changes include a decrease in cold temperature extremes, an increase in warm temperature extremes, an increase in extreme high sea levels, and an increase in the number of heavy precipitation events in a number of regions. These changes impact ecosystems and food security. Climate change will amplify existing risks and create new risks for natural and human systems [19]. This analysis aims to explore the relationship between severe weather events and intimate partner violence among Kenyan women.

\section{Materials and Methods}

Since the 1980s, the Demographic and Health Surveys (DHS) have been the main source of information about health and well-being for women and young children in lowand middle-income countries (LMICs). Since most LMICs conduct DHS surveys at 3- to 5-year intervals, DHS data can be used to study trends over time, and new topics (e.g., HIV testing and awareness) are added in response to emerging public health crises (e.g., the HIV pandemic). Since 2000, many Demographic and Health Surveys have included 
questions about intimate partner violence-emotional, physical, and sexual. In addition, many Demographic and Health Surveys release GPS coordinates for the approximate location of sampling clusters, allowing researchers to link outside data sources indexed by geographic location - to, for example, information on extreme weather events-with DHS survey participants [20].

The DHS surveys are intended to represent the total population of a nation. Sampling uses a multi-stage process to select households to be surveyed. The country is initially stratified by geographical regions, which are then further stratified into urban/rural. Clusters within each region are selected, and within these clusters, 25-30 households are randomly selected to interview [21].

For our analysis, we used harmonized DHS data from Integrated Public Use Microdata Series (IPUMS), which recodes variable names and codes to be consistent across time and space and supplies supplementary documentation about variables [22]. We used data from Kenya for survey years 2008 and 2014, along with the GPS location data collected for each survey cluster. GPS data are randomly displaced to provide for the confidentiality of the respondents. Urban clusters are displaced from $0-2 \mathrm{kms}$, and rural clusters are displaced from $0-5 \mathrm{kms}$, with an additional $1 \%$ of the rural clusters having a displacement of up to $10 \mathrm{kms}$. The displacement ensures the GPS coordinates of the cluster remain within the boundaries of the survey region [20].

The 2008 and 2014 Kenya DHS surveys randomly selected one woman from each household, who was of childbearing age (age 15-49) and had ever been married or lived with a man, to complete the Domestic Violence (DV) questionnaire. The DHS surveys use the broad term "domestic violence" to refer to violence experienced from a partner or husband and violence from other family members; we will be referring to violence from a partner or husband specifically as IPV. The questionnaires asked respondents whether they had experienced IPV and how often it occurred in the past 12 months (often, sometimes, or not at all). The survey questions addressed 12 different forms of IPV in the areas of emotional, sexual, and physical violence. All women who responded to at least one of the 12 IPV questions were included in this analysis. These variables were recorded into a single dichotomous variable. Those who responded with never or not at all in the past year on all 12 questions were coded as " 0 ", and those who responded with occurred often or sometimes in the past year on at least one of the 12 IPV questions were coded as "1". If a woman's response to any single question was unclear, the response was reported as "missing" for that variable. Appendix A includes the survey questions and response choices.

For the 2008 survey, Kenya was divided into 8 provinces (Central, Coast, Eastern, Nairobi, North Eastern, Nyanza, Rift Valley, and Western). Following the 2010 constitution, Kenya was reorganized into 47 counties, resulting in a different division of regions for the 2014 surveys. We converted the 8 provinces from the 2008 survey to match the 47 counties in 2014 using latitude and longitude coordinates in [23].

We used data from the Centre for Research on the Epidemiology of Disasters (CRED) Emergency Events Database (EM-DAT) to identify severe weather events in Kenya [24]. We identified weather events in the 2 years prior $(2006,2007,2012,2013)$ and the year of $(2008,2014)$ DHS data collection. For analysis purposes, we defined a severe weather event as a flood lasting 10 or more days. Though droughts are also reported by EM-DAT and can have a detrimental effect on agriculture, only two droughts were reported in the study period, and thus, droughts were not evaluated in this analysis.

All statistical analyses were conducted using StataC 16 [25]. We conducted a logistic regression with a mixed-methods model, grouped by the 47 counties in Kenya to estimate the odds ratios (OR) and 95\% confidence intervals (CI) for the association between living in a county that experienced an SWE and reporting experiences of IPV. Experiences of IPV were examined in an overall analysis (any reports of IPV in the past 12 months) and IPV specific analyses (emotional, physical, and sexual IPV). We then evaluated the relationship between a change in severe weather and experiences of IPV. We looked at the year prior to DHS data collection and the year of DHS data collection and created a variable indicating 
if SWEs went up, went down, or stayed the same in each county. Each of the final models was adjusted for urban/rural residence, if the woman's partner works in the agricultural industry, and if the partner drinks alcohol.

\section{Results}

The 2008 survey included 4903 women, and the 2014 survey included 4512 women. The mean age of the study population was 28.4 years. The majority of women (approximately $80 \%$ in both years) were married. More than half (54\%) achieved a primary level of education, while just under $20 \%$ of the study population had received no formal education. Complete demographic information on the study population can be found in Table 1.

Table 1. Demographic Characteristics of Study Population.

\begin{tabular}{ccc}
\hline Characteristics & Survey Year 2008 $(\boldsymbol{n}=\mathbf{4 9 0 3})$ & Survey Year 2014 $(\boldsymbol{n}=\mathbf{4 5 1 2})$ \\
\hline Urban/Rural Status & $\mathrm{N}(\%)$ & $\mathrm{N}(\%)$ \\
Urban & $1396(28.5)$ & $1642(36.4)$ \\
Rural & $3507(71.5)$ & $2870(63.6)$ \\
Age & & \\
$15-19$ & $220(5.5)$ & $153(3.4)$ \\
$20-29$ & $2062(42.1)$ & $1898(42.1)$ \\
$30-39$ & $1658(33.8)$ & $1580(35.0)$ \\
$40-49$ & $963(19.6)$ & $881(19.5)$ \\
Marital Status & & \\
Married & $3952(80.6)$ & $3583(79.4)$ \\
Living Together & $316(6.5)$ & $278(6.2)$ \\
Divorced/Widowed & $367(7.4)$ & $357(7.9)$ \\
Other & $268(5.5)$ & $296(6.5)$ \\
Highest Educational Level & $937(19.1)$ & $788(17.5)$ \\
None & $2647(54.0)$ & $2451(54.3)$ \\
Primary & $1319(26.9)$ & $1273(28.2)$ \\
Secondary or higher & $2950(60.2)$ & $2984(66.1)$ \\
Currently Working & $1942(39.7)$ & $1525(33.8)$ \\
Yes & $11(0.2)$ & $3(0.1)$ \\
No & &
\end{tabular}

In 2014, Kenya experienced a decrease in the number of women reporting IPV within the last year compared to 2008. In 2008, the prevalence of IPV ranged from a low of $8.6 \%$ in Wajir to a high of $68.1 \%$ in Baringo. The prevalence in 2014 was altogether lower, with a low of $6.3 \%$ in Garissa and a high of $54.1 \%$ in Bungoma. Figure 1 is a comparison by county of the prevalence of IPV for 2008 and 2014.

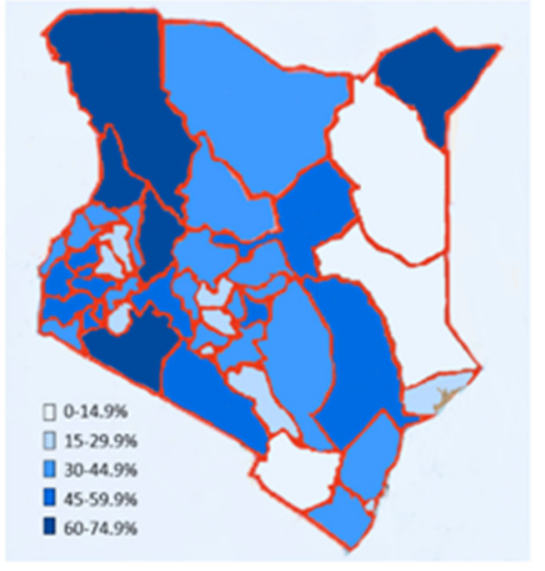

(a)

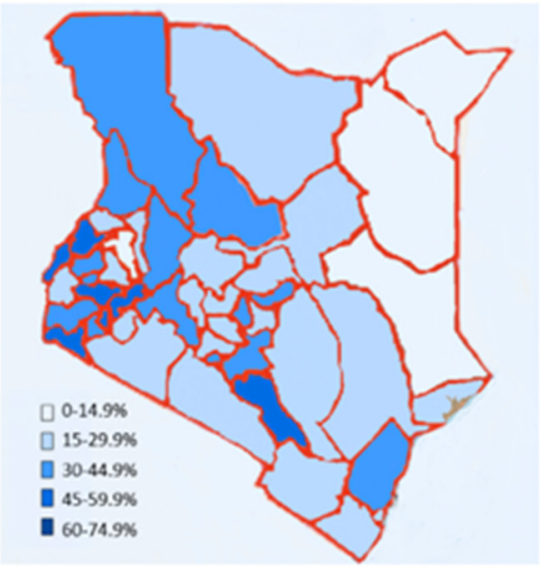

(b)

Figure 1. Prevalence of Interpersonal Violence per County in the Demographic and Health Surveys (DHS) Survey Years: (a) 2008; (b) 2014 . 
There were greater odds of reporting IPV among women whose partners worked in agriculture as compared to women whose partners did not work in agriculture ( $\mathrm{OR}=1.22$, 95\% CI: 1.10-1.36). There were also greater odds of reporting IPV in counties that experienced a severe flood when compared to counties that did not experience a severe flood $(\mathrm{OR}=1.60,95 \% \mathrm{CI}: 1.35-1.89)$. Additionally, there was a strong relationship between a partner drinking alcohol and reporting all forms of IPV (OR =2.38, 95\% CI: 2.17-2.62). These associations held true in both crude and adjusted models. Though living in a rural location was not associated with reporting IPV, rural residence was highly correlated with a partner working in the agricultural industry.

A change in the number of floods experienced by a county was associated with a change in the prevalence of IPV. If there was an increase in the number of floods during the survey year from the year prior to the survey year, there was an increase in the odds of reporting IPV (OR $=1.74,95 \%$ CI: 1.43-2.13). This held true for both physical violence $(\mathrm{OR}=2.01,95 \%$ CI: $1.63-2.49)$ and sexual violence $(\mathrm{OR}=1.48,95 \% \mathrm{CI}: 1.07-2.05)$ but not emotional abuse (OR $=1.03,95 \%$ CI: $0.82-1.30)$. Table 2 provides complete results.

Table 2. Odds of Having Experienced Intimate Partner Violence by Severe Flood Events N = 9415 for 47 County Data.

\begin{tabular}{|c|c|c|c|c|c|c|c|c|}
\hline & \multicolumn{2}{|c|}{ All Forms IPV } & \multicolumn{2}{|c|}{ Emotional IPV } & \multicolumn{2}{|c|}{ Physical IPV } & \multicolumn{2}{|c|}{ Sexual IPV } \\
\hline & OR & $(95 \% \mathrm{CI})$ & OR & $(95 \% \mathrm{CI})$ & OR & $(95 \% \mathrm{CI})$ & OR & $(95 \% \mathrm{CI})$ \\
\hline \multicolumn{9}{|l|}{ Unadjusted: } \\
\hline Severe Flood & 1.56 & $(1.31,1.85)$ & 0.90 & $(0.74,1.09)$ & 1.86 & $(1.55,2.23)$ & 1.57 & $(1.19,2.07)$ \\
\hline $\begin{array}{l}\text { Partner works } \\
\text { in agriculture }\end{array}$ & 1.25 & $(1.13,1.38)$ & 1.22 & $(1.09,1.36)$ & 1.31 & $(1.18,1.46)$ & 1.26 & $(1.07,1.46)$ \\
\hline Partner drinks alcohol & 2.37 & $(2.16,2.61)$ & 2.31 & $(2.08,2.55)$ & 2.56 & $(2.31,2.84)$ & 2.70 & $(2.33,3.12)$ \\
\hline Urban/Rural residence & 1.05 & $(0.95,1.16)$ & 0.94 & $(0.84,1.05)$ & 1.17 & $(1.04,1.31)$ & 1.02 & $(0.87,1.20)$ \\
\hline \multicolumn{9}{|l|}{ Adjusted models: } \\
\hline Severe Flood & 1.60 & $(1.35,1.89)$ & 0.92 & $(0.76,1.12)$ & 1.91 & $(1.59,2.29)$ & 1.61 & $(1.22,2.12)$ \\
\hline $\begin{array}{l}\text { Partner work } \\
\text { in agriculture }\end{array}$ & 1.22 & $(1.10,1.36)$ & 1.24 & $(1.10,1.39)$ & 1.25 & $(1.12,1.40)$ & 1.22 & $(1.04,1.44)$ \\
\hline Partner drinks alcohol & 2.38 & $(2.17,2.62)$ & 2.30 & $(2.08,2.55)$ & 2.58 & $(2.33,2.86)$ & 2.71 & $(2.34,3.13)$ \\
\hline Urban/Rural residence & 0.95 & $(0.85,1.06)$ & 0.87 & $(0.77,0.98)$ & 1.05 & $(0.93,1.18)$ & 0.92 & $(0.77,1.09)$ \\
\hline \multicolumn{9}{|l|}{ Change in Flood Pattern } \\
\hline Increase ( 0 to 1$)$ & 1.74 & $(1.43,2.13)$ & 1.03 & $(0.82,1.30)$ & 2.01 & $(1.63,2.49)$ & 1.48 & $(1.07,2.05)$ \\
\hline Decrease (1 to 0 ) & 0.78 & $(0.66,0.93)$ & 0.89 & $(0.74,1.07)$ & 0.67 & $(0.56,0.81)$ & 0.74 & $(0.58,0.95)$ \\
\hline Stay Same (1 to 1$)$ & 0.80 & $(0.54,1.19)$ & 0.56 & $(0.37,0.85)$ & 0.86 & $(0.57,1.31)$ & 1.27 & $(0.71,2.28)$ \\
\hline
\end{tabular}

\section{Discussion}

Our findings suggest that an increase in SWEs is correlated with an increase in physical and sexual violence. This same increase was not seen with emotional violence. Further studies examining this observation would be beneficial when focusing on interventions to decrease IPV. We identified a relationship between experiences of IPV and SWEs in Kenya during the study time period. There was a 1.6 increase in IPV odds among those who lived in counties that experienced an SWE. The results of this work further support the growing body of research that suggests a relationship between climate change-related weather events and violence against women $[6,8,16,26]$. The current body of literature has found that women are adversely affected by climate change, which has been documented during and after a number of climate events, including heatwaves, hurricanes, and cyclones [1,2,5]. As noted earlier by Gevers et al. (2020), the physical demands on women increase with climate change. In addition, as was noted by UN Women, an increase in cyclone activity 
was correlated with an increase in seeking DV counseling. Our findings support previous literature and further the knowledge of the impacts of SWEs on women.

Previous studies have shown a correlation between domestic violence and the consumption of alcohol by a male partner. A study among pregnant women in Kenya noted that those who experienced partner violence were more likely to have a partner who consumed alcohol $[14,27]$. Similarly, Camey et al. noted an increase in alcohol use among men in Australia coping with stress due to droughts (2020). The compounding effect of climate change and alcohol consumption places women who have a husband working in agriculture at higher risk for experiencing IPV. Our results support this body of research because we identified a 2.38 increase in odds of IPV among those whose partners consumed alcohol.

IPV has progressively become a prominent issue both within Kenya and globally. Gender-based violence (GBV) is any act against a person based on their gender. According to UN Women (n.d.), GBV is a violation of basic human rights, and IPV has now become a human rights issue that has changed from a private concern within a family to a public concern. The Constitution of Kenya 2010 states that all people should be free from any form of violence, and non-action against violence is equal to accepting it, which perpetuates its existence [28]. In 2015, the United Nations General Assembly set the Sustainable Development Goals (SDG), SDG 5.2: eliminate all forms of violence against all women and girls in public and private spheres, including trafficking and sexual and other types of exploitation.

There were major differences in the prevalence of reported IPV across regions, differences that merit further study to determine whether their cause is economic, a variation across ethnic groups, or due to some other factor. In 2014, Kenya experienced a decrease in the number of women reporting IPV within the last year compared to 2008. This decrease may be due, in part, to the legislation change and the changing attitudes of men and women regarding IPV. In the Kenyan DHS surveys, women and men were asked questions regarding their attitudes towards IPV (i.e., views on when a husband is justified in hitting or beating his wife). Between 2008 and 2014, there was a decrease in the percentage of both women (29.8 to 24.9) and men (22.4 to 19.0) who consider hitting or beating a woman to be justified in some circumstances. The odds of a woman justifying beating or hitting were greater among women who experienced IPV in the past year compared to those who did not experience IPV. This change in attitude and the decrease in the number of women reporting IPV may be related to the Kenyan legislation change (as embodied in the new Constitution) that made IPV a public concern.

A number of limitations should be considered when interpreting the results of this study. The extreme weather events may have been more localized in their effects than the geographic units we used in our analysis. For example, flooding may only have occurred on agricultural land that was near a body of water (river or coastline), while the rest of the county was not affected. It is possible that women in the areas affected by flooding in a county were more likely to experience IPV, but the effect is diluted if most of the land in the county was not affected by flooding. More advanced research methods allowing for more precise location of floods and respondents would provide more accurate information. The measures of IPV were based on self-reporting and, thus, potentially underreported, which may have underestimated our results. The variables analyzed for this research were unique to the 2008 and 2014 Kenyan data sets, which limited the number of years available for analysis. While the county variation in IPV rates was not cross-validated with police reports, studies [29,30] suggest that rural women in Kenya and elsewhere do not report IPV cases. Similarly, this could have led to an underestimation of our final results. The next DHS survey for Kenya should be completed in 2021. This analysis could be rerun using data from this survey along with severe weather events to determine if the findings hold true. However, despite these limitations, this analysis has a number of strengths, including representative sampling across Kenya, a large sample size that 
allowed for adequate control of potential confounding variables, and a comprehensive questionnaire that included 12 measures of IPV.

\section{Conclusions}

Women are key stakeholders when it comes to climate change and violence. Over half of Kenyan rural women experience some form of IPV in their lifetime [31]. Moreover, climate change unequally impacts women due to their lower socioeconomic status and not being accorded the same basic human rights as their male counterparts [32]. Women need to be included at the decision-making table when developing interventions to combat climate change and increase protections for women. In Kenya, parliament is composed of $78 \%$ men and $22 \%$ women [33]. This imbalance of decision-making capacity needs to be rectified for women to take an equal voice in climate change.

Climate change and the resulting severe weather events continue to challenge the world [34]. As these challenges persist, interventions to both increase protection for women and raise women's status are needed to mitigate women's risk. Climate action is an essential component in the ongoing fight to eliminate violence against women and girls. This analysis adds to the urgency of addressing gender-based violence in all forms alongside action to stop environmental degradation and gender-based violence and demonstrates that the two issues often need to be addressed together.

Author Contributions: Conceptualization, E.M.A. and L.M.; methodology E.M.A., L.M. and J.R.H.; software, J.R.H. and E.M.A.; formal analysis, E.M.A., L.M. and J.R.H.; data curation, J.R.H.; writingoriginal draft preparation, J.R.H., E.M.A. and L.M.; writing-review and editing, E.M.A. and L.M.; visualization, E.M.A. and L.M.; supervision, E.M.A. and L.M.; project administration, E.M.A. and L.M. All authors have read and agreed to the published version of the manuscript.

Funding: This research received no external funding.

Institutional Review Board Statement: Ethical review and approval were waived for this study as the data used is publicly available and deidentified.

Informed Consent Statement: Informed consent was obtained from all participants included in IPUMS-DHS. Use of this data for secondary data analysis did not require additional consent.

Data Availability Statement: Publicly available datasets were analyzed in this study. The data can be found at IPUMS-DHS: https://www.idhsdata.org/idhs/index.shtml and EM-DAT: https:/ / www.emdat.be/ (accessed on 10 November 2021).

Conflicts of Interest: The authors declare no conflict of interest.

\section{Appendix A. DV Questions from 2008-2009 and 2014 DHS Survey}

Appendix A.1. DV Questions Pre-Survey Statement

Now, I would like to ask you questions about some other important aspects of a woman's life. You may find some of these questions very personal. However, your answers are crucial for helping to understand the condition of women in Kenya. Let me assure you that your answers are completely confidential and will not be told to anyone and no one else in your household will know that you were asked these questions.

Currently Married/Married Living with A Man ___ (respondents taken to DV from partner questions).

Formerly Married/Lived With A Man (Read In Past Tense And Use 'Last' With Husband/Partner) (respondents taken to DV from partner questions).

Never Married/Married Never Lived with A Man (respondents taken to DV from other people).

Appendix A.2. Now I Need to Ask Some More Questions about Your Relationship with Your (Last) (Husband/Partner). Did Your (Last) (Husband/Partner) Ever

(a) Say or do something to humiliate you in front of others? 
(b) Threaten to hurt or harm you or someone you care about?

(c) Insult you or make you feel bad about yourself?

(d) Push you, shake you, or throw something at you?

(e) Slap you?

(f) Twist your arm or pull your hair?

(g) Punch you with his fist or with something that could hurt you?

(h) Kick you, drag you, or beat you up?

(i) Try to choke you or burn you on purpose?

(j) Threaten or attack you with a knife, gun, or any other weapon?

(k) Physically force you to have sexual intercourse with him even when you did not want to?

(l) Force you to perform any sexual acts you did not want to?

Appendix A.3. For Each of the above Questions a-l That a Woman Answered Yes, They Were Then Asked This Follow-Up Question

How often did this happen during the last 12 months: often, only sometimes, or not at all?

(1) Often

(2) Sometimes

(3) Not at all

\section{References}

1. Anastario, M.; Shehab, N.; Lawry, L. Increased gender-based violence among women internally displaced in Mississippi 2 years post-Hurricane Katrina. Disaster Med. Public Health Prep. 2009, 1, 18-26. [CrossRef] [PubMed]

2. CARE International. Rapid Gender Analysis Cyclone Pam, Vanuatu. Available online: https://care.ca/wp-content/uploads/20 18/12/RGA-Cyclone-Pam-Vanuatu-7-April-2015.pdf (accessed on 15 March 2021).

3. Noelke, C.; McGovern, M.; Corsi, D.; Jimenez, M.; Stern, A.; Wing, I.; Berkman, L. Increasing ambient temperature reduces emotional well-being. Environ. Res. 2016, 151, 124-129. [CrossRef] [PubMed]

4. Michel, S.J.; Wang, H.; Selvarajah, S.; Canner, J.K.; Murrill, M.; Chi, A.; Efron, D.T.; Schneider, E.B. Investigating the relationship between weather and violence in Baltimore, Maryland, USA. Injury 2016, 47, 272-276. [CrossRef] [PubMed]

5. Sanz-Barbero, B.; Linares, C.; Vives-Cases, C.; González, J.L.; López-Ossorio, J.J.; Díaz, J. Heat wave and the risk of intimate partner violence. Sci. Total Environ. 2018, 644, 413-419. [CrossRef] [PubMed]

6. United Nations Development Programme. Why Climate Change Fuels Violence against Women. Available online: https:/ / undp.org/blogs/why-climate-change-fuels-violence-against-women (accessed on 16 January 2021).

7. eScholarship. Access to Water in a Nairobi Slum: Women's Work and Institutional Learning. Available online: https:// escholarship.org/uc/item/7h52n89v (accessed on 10 June 2021).

8. Camey, I.; Sabater, L.; Owren, C.; Boyer, A. Gender-based violence and environment linkages. In The Violence of Inequality; Wen, J., Ed.; IUCN: Gland, Switzerland, 2020; Available online: https:/ / portals.iucn.org/library/sites/library/files/documents / 2020-002-En.pdf (accessed on 19 April 2021).

9. ReliefWeb. Why Kenya's Seasonal Rains Keep Failing and What Needs to Be Done-Kenya. Available online: https://reliefweb. $\mathrm{int} /$ report/kenya/why-kenya-s-seasonal-rains-keep-failing-and-what-needs-be-done (accessed on 7 August 2020).

10. EOS. Climate Change Uproots Global Agriculture. Available online: https:/ / eos.org/features/climate-change-uproots-globalagriculture (accessed on 18 September 2021).

11. UNCCD. Climate Change in Kenya: Focus on Children. Available online: https://www.unccd.int/sites/default/files/relevantlinks/2017-06/climatechangekenya2010web.pdf (accessed on 7 August 2020).

12. USAID. Agriculture and Food Security: Kenya. Available online: https://www.usaid.gov/kenya/agriculture-and-food-security (accessed on 6 August 2020).

13. D'Alessandro Stephen, P.; Caballero, J.; Lichte, J.; Simpkin, S. Kenya: Agricultural Sector Risk Assessment. Agriculture Global Practice Technical Assistance Paper; World Bank: Washington, DC, USA, 2015. Available online: https: / / openknowledge.worldbank.org/ handle/10986/23350. (accessed on 10 November 2021).

14. Gillum, T.L.; Doucette, M.; Mwanza, M.; Munala, L. Exploring Kenyan Women's Perceptions of Intimate Partner Violence. J. Interpers. Violence 2018, 13, 2130-2154. [CrossRef] [PubMed]

15. Obi, S.N.; Ozumba, B.C. Factors Associated with Domestic Violence in South-East Nigeria. J. Obstet. Gynaecol. 2007, 1, 75-78. [CrossRef] [PubMed]

16. Intergovernmental Panel on Climate Change. Impacts of $1.5^{\circ} \mathrm{C}$ Global Warming on Natural and Human Systems. Available online: https://helda.helsinki.fi/handle/10138/311749 (accessed on 10 June 2021). 
17. Levy, B.S.; Sidel, V.W.; Patz, J.A. Climate change and collective violence. Annu. Rev. Public Health 2017, 38, 241-257. [CrossRef] [PubMed]

18. Kenya National Bureau of Statistics; Ministry of Health/Kenya; National AIDS Control Council/Kenya; Kenya Medical Research Institute; National Council for Population and Development/Kenya. Kenya Demographic and Health Survey 2014.2015. Available online: http:/ / dhsprogram.com/pubs/pdf/FR308/FR308.pdf (accessed on 18 November 2020).

19. IPCC. Climate Change and Land: An IPCC Special Report on Climate Change, Desertification, Land Degradation, Sustainable Land Management, Food Security, and Greenhouse Gas Fluxes in Terrestrial Ecosystems. Available online: https://www.ipcc.ch/ srccl/ (accessed on 10 June 2021).

20. The DHS Program. GPS Data Collection. Available online: https://dhsprogram.com/methodology/gps-data-collection.cfm (accessed on 19 April 2021).

21. The DHS Program. Analyzing DHS Data. Available online: https://dhsprogram.com/data/Guide-to-DHS-Statistics/ Analyzing_DHS_Data.htm\#: :text=Most\%20DHS\%20surveys\%20use \%20a,of\%20clusters\%20to\%20be\%20selected.\&text= Following\%20the \%20listing\%20of\%20the,sampling\%20in\%20the\%20selected\%20cluster (accessed on 19 April 2021).

22. Boyle, E.; King, M.; Sobeck, M. IPUMS Demographic and Health Surveys. Version 8 [Dataset]; IPUMS and ICF: Minneapolis, MN, USA, 2020. [CrossRef]

23. TC Cloud Solutions LLC. EasyMapMaker. 2019. Available online: https://www.easymapmaker.com/ (accessed on 15 March 2021).

24. Centre for Research on the Epidemiology of Disasters. Dat: The International Disasters Database. Available online: https: //www.emdat.be/ (accessed on 14 April 2021).

25. StataCorp. Stata Statistical Software: Release 16; StataCorp LLC: College Station, TX, USA, 2019.

26. UN Women. Women and the Environment. Available online: https://www.unwomen.org/en/news/in-focus/end-violenceagainst-women/2014/environment (accessed on 3 March 2021).

27. Makayoto, L.A.; Omolo, J.; Kamweya, A.M.; Harder, V.S.; Mutai, J. Prevalence and associated factors of intimate partner violence among pregnant women attending Kisumu District Hospital, Kenya. Matern. Child Health J. 2013, 17, 441-447. [CrossRef] [PubMed]

28. Aura, R. Situational Analysis and the Legal Framework on Sexual and Gender-Based Violence in Kenya: Challenges and Opportunities. Available online: http:/ / kenyalaw.org/kl/index.php?id=4512 (accessed on 15 April 2021).

29. Leburu-Masigo, Goitseone Emelda. Urban and Rural Women's Experiences of Intimate Partner Violence. S. Afr. J. Soc. Work. Soc. Dev. 2019, 31, 14. [CrossRef]

30. Odero, M.; Hatcher, A.M.; Bryant, C.; Onono, M.; Romito, P.; Bukusi, E.A.; Turan, J.M. Responses to and resources for intimate partner violence: Qualitative findings from women, men, and service providers in rural Kenya. J. Interpers. Violence 2014, 29, 783-805. [CrossRef] [PubMed]

31. Hatcher, A.M.; Romito, P.; Odero, M.; Bukusi, E.A.; Onono, M.; Turan, J.M. Social context and drivers of intimate partner violence in rural Kenya: Implications for the health of pregnant women. Cult. Health Sex. 2013, 15, 404-419. [CrossRef] [PubMed]

32. EJS Center. Why the Voices of African Women Are so Important in the Fight against Climate Change. Available online: https: / / www.ejscenter.org/news / why-the-voices-of-african-women-are-so-important-in-the-fight-against-climate-change/ (accessed on 10 June 2021).

33. Reuters. Kenya's Top Judge Advises Parliament to Dissolve over Lack of Women. Available online: https://www.reuters.com/ article/us-kenya-women-politics/kenyas-top-judge-advises-parliament-to-dissolve-over-lack-of-women-idUSKCN26C33X (accessed on 15 April 2021).

34. Rezaeian, M. The association between natural disasters and violence: A systematic review of the literature and a call for more epidemiological studies. J. Res. Med. Sci. 2013, 18, 1103-1107. [PubMed] 